\title{
Predicting Children's Nutritional Status Using QUEST Method
}

\author{
Izzati Rahmi $^{\text {a }}$, HazmiraYozza ${ }^{a}$, HafifatulAuliyaRahmy \\ ${ }^{a}$ Mathematics Department, Faculty of Mathematics and Natural Science, Andalas University, Padang, Limau \\ Manih, 25162, Indonesia \\ ${ }^{\mathrm{b}}$ Nutrition Department, Faculty of Public Health, Andalas University, Padang, Jati VI No 12 Kelurahan Jati \\ Baru, 25129, Indonesia
}

Corresponding Author: Izzati Rahmi

\begin{abstract}
Concerning WHO's standard of nutritional status, the Indonesian Ministry of Health office's result of monitoring nutritional status in 2017 discovered a nutritional problem among children in Padang, West Sumatra. This study was aimed at determining factors that affect the nutritional status and their malnutrition level for the children under five years in Padang, West Sumatera. Data analysis was conducted using a classification tree technique, namely the QUEST method. By the research, the QUEST method analysis showed some underweight and severely underweight cases were found to be common among children under three years of age. On the one hand, severely underweight and underweight cases were commonly identified among female children. On the other, the prevalence of overweight case is common among the male. At last, the analysis of underthree male children indicated that overweight cases were found in children who did not receive exclusive breastfeeding.
\end{abstract}

Keywords: nutritional status; classifications; QUEST method.

\section{INTRODUCTION}

Nutritional status is an important indicator of a national health parameter. The nutritional status describes a balance between the body's needs and nutritional intake. If the nutritional needs are optimally met, a normal status will be achieved. In this case, nutrition is considered as the first signal of the emergence of commonly occurring degenerative diseases [1].

In relation to this nutritional issue, children under five years of age are the most vulnerable group for having malnutrition problems. Malnutrition in underfivechildren may causea failure of growth and developmentand a growingprevalence of morbidity and mortality. Not only does malnutrition at the early stages of life affect the child's health outcomes but it also has a serious impact on their determinants of livelihood such as on their physical and intellectual growth, school performance, and eventual future earnings and productivity $[2,3]$. Thus, monitoring children'snutritional status is a fundamental instrument for measuring a population's health [4].

According to the result of monitoring nutritional status by the Ministry of Health office of the Republic of Indonesian, there has been a nutritional problem in Padang city of West Sumatera, Indonesian. Based on the weight-for-age factor, in 2015 , there were only $79.2 \%$ of under-five children who had a normal nutritional status, while $2.9 \%$ of them were severely underweight; $15.8 \%$ were underweight, and $1.1 \%$ were overweight [5]. In 2016, there has been a decrease (down to $11.5 \%$ ) in the severely underweight and underweight cases, which indicates a decrease in malnutrition cases in Padang. However, this figure is still greater than WHO's standard, where a region is 
categorized to have no nutritional problems if the case of severely underweight and underweight is less than 10\% [6]. Therefore, since under-five children are very susceptible to nutrition problems, it becomes necessary to identify factors that influence nutrition problems among them. Furthermore, this investigation may provide a ground for evaluating related policies concerning the nutrition problem of children.

Several studies have been conducted related to the factors affecting the nutritional status of under-five children. Direct factors are nutrition intake and infectious disease [7] while indirect factors are children's age, birth weight, mother education's level, mother's employment status, family income, the number of children in family, knowledge on nutrition and exclusive breastfeeding status [8-12].

This research offers the application of the classification tree method to model the nutritional status of children under five years of age and identify factors that may affect it.This is the most recommended method to assess the causal relationship between explanatory variables and response when the analyzed data have high complexity with a large number of observations and variables. Among several methods of tree structure classification, the QUEST (Quick, Unbiassed, Efficient, Statistical Tree) method is selected as it is a relatively new method compared to others. Several previous studies that used the QUEST method, among others, Ramezani et al, used the QUEST method to identify two types of diabetes [13], and Abdurrahman et al. used the QUEST method for grouping patients based on liver disease [14].

By means of the QUEST method, data were split based on the variables that were suspected of distinguishing the children's nutritional status. The process of splitting was done so that only significant variables were involved in the resulting model. In addition, the explanatory variables were sorted based on their influence on the response. Determining factors that affected the nutritional status and the level of malnutrition among underfive children in Padang, West Sumatera, were discussed.

\section{MATERIAL AND METHODS Study Design}

This study was designed to determine factors that affect the nutritional status of children under five years. Assessment of nutritional status was conducted based on weight-for-age z-score and then converted according to WHO standard in the following formula [6]:

$$
Z-\text { score }=\frac{(\text { actual weight }- \text { reference median })}{\text { reference standard deviation }}
$$

WHO standard reference defines four levels of nutritional status, namely severely underweight, underweight, normal, and overweight. Cut-off points are as follows: Z-score <-3SD is for severely underweight, -3SD $<\mathrm{Z}$-score $<-2 \mathrm{SDis}$ for underweight, $-2 \mathrm{SD}<\mathrm{Z}$-score $<2 \mathrm{SD}$ is for normal, and Z-score $>2$ SDis for overweight. In this study, factors suspected to affect the children's nutritional status include the children's sex, age, birth weight, number in a family, family income, mother's education level, mother's employment status, mother's knowledge on nutrition, and exclusive breastfeeding status.

\section{Sampling Design}

This study used primary data obtained directly from data sources, i.e.,317 mothers whose children aged 0-60 monthsin Padang West Sumatra.The survey was carried out in four districts in Padang(namely Lubuk Kilangan, Kuranji, West Padang, and Nanggalo districts), which were selected purposively by considering the city's representation of social-economic condition. The survey was conducted at several Posyandu-s (maternal and children health services), daycares, and housings, which were chosenthrough the purposive sampling technique. This primary data were related to eight factors that were predicted to affect nutritional status. Primary data, including the data of 
children's weight, were obtained directlythrough interviews by using a questionnaire as a guide.

\section{Method}

Data were analyzedusing a classification tree technique. A classification tree is a rule for predicting the class of an object from the values of its predictor variables. The tree is constructed by recursively partitioning a learning sample of data in which the class label and the values of the predictor variables for each case are known. Each partition is represented by a node in the tree diagram [15].

There are many classifications of tree algorithms, i.e.,CHAID, CART, CRUISE, and QUEST. This research chose to use QUEST (Quick, Unbiassed, Efficient, Statistical Tree). QUEST Tree diagram is based on linear combination splits, which are usually shorter and more accurate than the same trees based on univariate splits [16].

Based on the result of the tree diagram, significant variables that affected the nutritional status of children under five years could be analyzed. The characteristics of children in each group were identified, and predictions of their nutritional status were also obtained. The number of the group was determined by the number of terminal nodes produced. Interpretation of the tree diagram was also made by evaluating the distribution of observations in each node formed $[15,16]$.

\section{RESULT AND DISCUSSION Descriptions Analysis}

Based on the Z-score calculation using Eq. (1), the distribution of nutritional status for the observed children are given in Table 1.

Table 1 showed that the prevalence of malnutrition in under-five children was still high.The prevalence of severely underweight $(0.94 \%)$ and underweight $(7.89 \%)$ was relatively low $(8.93 \%$ altogether), and the prevalence of overweight cases was very high, i.e., $29.02 \%$. According to WHO standards, a region is defined to have nutritional problems if the prevalence of severely underweight and underweight is less than $10 \%$, and the prevalence of overweight is less than 5\% [6]. Table 1 confirmedthat under-five children in Padang were still susceptible to malnutrition and underwent a nutritional problem that needed special attention.

Table1: Distribution of Nutritional Status of Children
\begin{tabular}{|l|c|c|}
\hline Nutritional Status & Frequency & Percentage \\
\hline Severely underweight & 3 & 0.94 \\
\hline Underweight & 25 & 7.89 \\
\hline Normal & 197 & 62.15 \\
\hline Overweight & 92 & 29.02 \\
\hline Total & $\mathbf{3 1 7}$ & $\mathbf{1 0 0}$ \\
\hline
\end{tabular}

Furthermore, Table 2 presented the characteristics of under-five children based on each categorical variable involved:

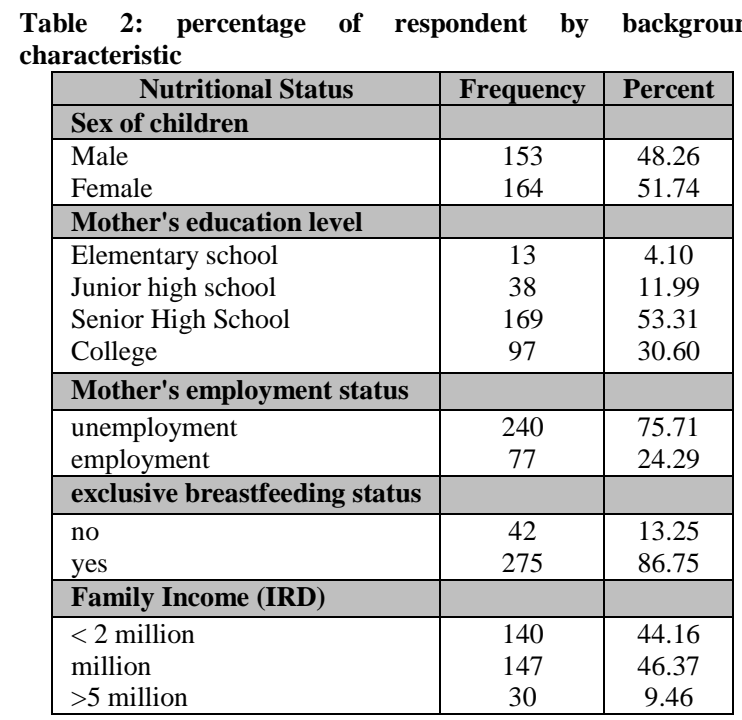

Table 2 showed that no significant difference was found between male and female children observed, i.e., $48.26 \%$ and $51.74 \%$, respectively. It was also discovered that $\pm 30 \%$ of the respondents were college graduates. It means that the majority of children's mothers had only elementary and secondary levels of formal education. Furthermore, most of the mothers (75.71\%)were unemployed, and most of the children $(86.75 \%)$ received exclusive breastfeeding, which indicated most of the mothers' awareness of the importance of exclusive breastfeeding. Finally, in terms of 
family income, most of the respondents came from low to middle socioeconomic families.

Contingency tables between each categorical variables and nutritional status of children were given in Table 3.It was noted that the percentage written in parentheses was the percentage of total observations in each category of independent variables used.

\begin{tabular}{|c|c|c|c|c|c|}
\hline \multirow[t]{2}{*}{ No } & \multirow{2}{*}{ Variables } & \multicolumn{4}{|c|}{ Nutritional Status } \\
\hline & & Severely Underweight & Underweight & Normal & Overweight \\
\hline \multirow[t]{3}{*}{1.} & Sex of Children & & & & \\
\hline & 1. male & $2(1.35 \%)$ & $5(3.9 \%)$ & $78(51 / 0 \%)$ & $67(43,8 \%)$ \\
\hline & 2. female & $1(0.65 \%)$ & $19(11.6 \%)$ & $119(72.6 \%)$ & $25(15.25)$ \\
\hline \multirow[t]{5}{*}{2.} & Mother's education level & & & & \\
\hline & Elementary school & $1(7.7 \%)$ & $1(7.7 \%)$ & $7(53 / 8 \%)$ & $4(30.8 \%)$ \\
\hline & Junior high school & $0(0.0 \%)$ & $7(18.4 \%)$ & $21(55.3 \%)$ & $10(26.8 \%)$ \\
\hline & Senior High School & $1(0.6 \%)$ & $13(7.7 \%)$ & $107(63.3 \%)$ & $48(28.4 \%)$ \\
\hline & College & $1(1.0 \%)$ & $4(4.1 \%)$ & $62(63.9 \%)$ & $30(30.9 \%$ \\
\hline \multirow[t]{3}{*}{3.} & Mother's employment status & & & & \\
\hline & unemployment & $2(0.8 \%)$ & $9(7.9 \%)$ & $150(62.5 \%)$ & $69(28.8 \%)$ \\
\hline & employment & $1(1.3 \%)$ & $6(7.8 \%)$ & $47(61.0 \%)$ & $23(29.9 \%)$ \\
\hline \multirow[t]{3}{*}{4.} & Exclusive breastfeeding status & & & & . \\
\hline & yes & $0(0.0 \%)$ & $4(9.5 \%)$ & $26(61.9 \%)$ & $12(28.6 \%)$ \\
\hline & no & $3(1.1 \%)$ & $21(7.6 \%)$ & $71(52.2 \%)$ & $80(29.1 \%)$ \\
\hline \multirow[t]{4}{*}{5.} & Family Income (IRD) & & & & \\
\hline & 1. $<2$ million & $1(0.7 \%)$ & $12(8.6 \%)$ & $88(62.9 \%)$ & $39(27.9 \%)$ \\
\hline & 2. 2-5 million & $1(0.7 \%)$ & $12(8.2 \%)$ & $87(59.2 \%)$ & $47(32.05)$ \\
\hline & 3.> 5 million & $1(3.3 \%)$ & $1(3.35)$ & $22(73.3 \%)$ & $6(20.0 \%)$ \\
\hline
\end{tabular}

Table 3 informs that with regard to children's sex criteria, severely underweight and underweight were more commonly found in female children, and overweight was more common in male children. In addition, normal nutrition cases were higher in female than in male children. In relation to mother's education level, severely underweight and underweight cases were more commonly found in mothers with elementary and junior high schools of formal education. There was no significant difference in the incidence of overweight cases among the four mother's education level. Normal nutrition prevalence was higher in children whose mothers were in high school and college/university graduates. In terms of mothers' employment status, there was no significant difference in the nutritional status among children whose mothers worked and did not work. As to exclusive breastfeeding criterion, Table 3 shows that three children who did not receive exclusive breastfeeding suffered from severely underweight problem. Furthermore, the prevalence of underweight and overweight did not differ between children who received and did not receive exclusive breastfeeding while the prevalence of normal nutritional status was higher among children who did not receive exclusive breastfeeding. With reference to family income status, the prevalence of each category of nutritional status was almost the same between families with the income of less than two million rupiahs and families with the income of 2-5 million rupiahs. However, the trend was different for families with an income of more than five million rupiahs. The data also indicated that the prevalence of underweight was higher in families with the incomes of less than two million rupiahs and families with the income between 2-5 million rupiahs.

\section{QUEST Analysis Result}

QUEST Tree diagram presented in Figure 1illustrated variables that significantly influenced the nutritional status of children under five consecutively included children's age, sex, and exclusive breastfeeding status. A 9-terminal node was formed and indicated that 317 children could be classified into nine groups. Prediction of the nutritional status of children in each group and its characteristics using the QUEST method was presented in Table 4. 
Table 4: Characteristics and Predictions of Nutritional Status of Children

\begin{tabular}{|c|l|c|}
\hline Group & \multicolumn{1}{|c|}{ Characteristics } & Predictions of Nutritional Status \\
\hline 1 & Age <23 months. & Normal \\
\hline 2 & Age between 23 to 36 months, female, do not receive exclusive breastfeeding. & Overweight \\
\hline 3 & Age between 23 to 36 months, female, receive exclusive breastfeeding. & Normal \\
\hline 4 & Age between 23 to 27 months, male. & Normal \\
\hline 5 & Age between 27 to 36 months, male. & Overweight \\
\hline 6 & Age between 36 to 37.4 months, & Overweight \\
\hline 7 & Age between 37.4 to 51.1 months, female & Normal \\
\hline 8 & Age $>51.1$ months, female. & Overweight \\
\hline 9 & Age $>37.4$ months, male. & Overweight \\
\hline
\end{tabular}

Table 5: Level of Accuracy of Estimation of Nutritional Status of Children Under Five Years Using QUEST Method

\begin{tabular}{|l|c|c|c|c|c|}
\hline \multirow{2}{*}{ Observed } & \multicolumn{4}{|c|}{ Predicted } & \% corrected \\
\cline { 2 - 6 } & Severely Underweight & Underweight & Normal & Overweight & \\
\hline Severely underweight & 0 & 0 & 3 & 0 & $0.0 \%$ \\
\hline Underweight & 0 & 0 & 22 & 3 & $0.0 \%$ \\
\hline Normal & 0 & 0 & 184 & 13 & $93.4 \%$ \\
\hline Overweight & 0 & 0 & 13 & 79 & $85.9 \%$ \\
\hline Overall Percentage & $0.0 \%$ & $0.0 \%$ & $70.0 \%$ & $30.0 \%$ & $83.0 \%$ \\
\hline
\end{tabular}

1. severely underweight

2. underweight

3. normal

4. overweight

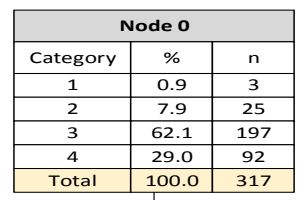

Age $(p-v a l=0.000)$

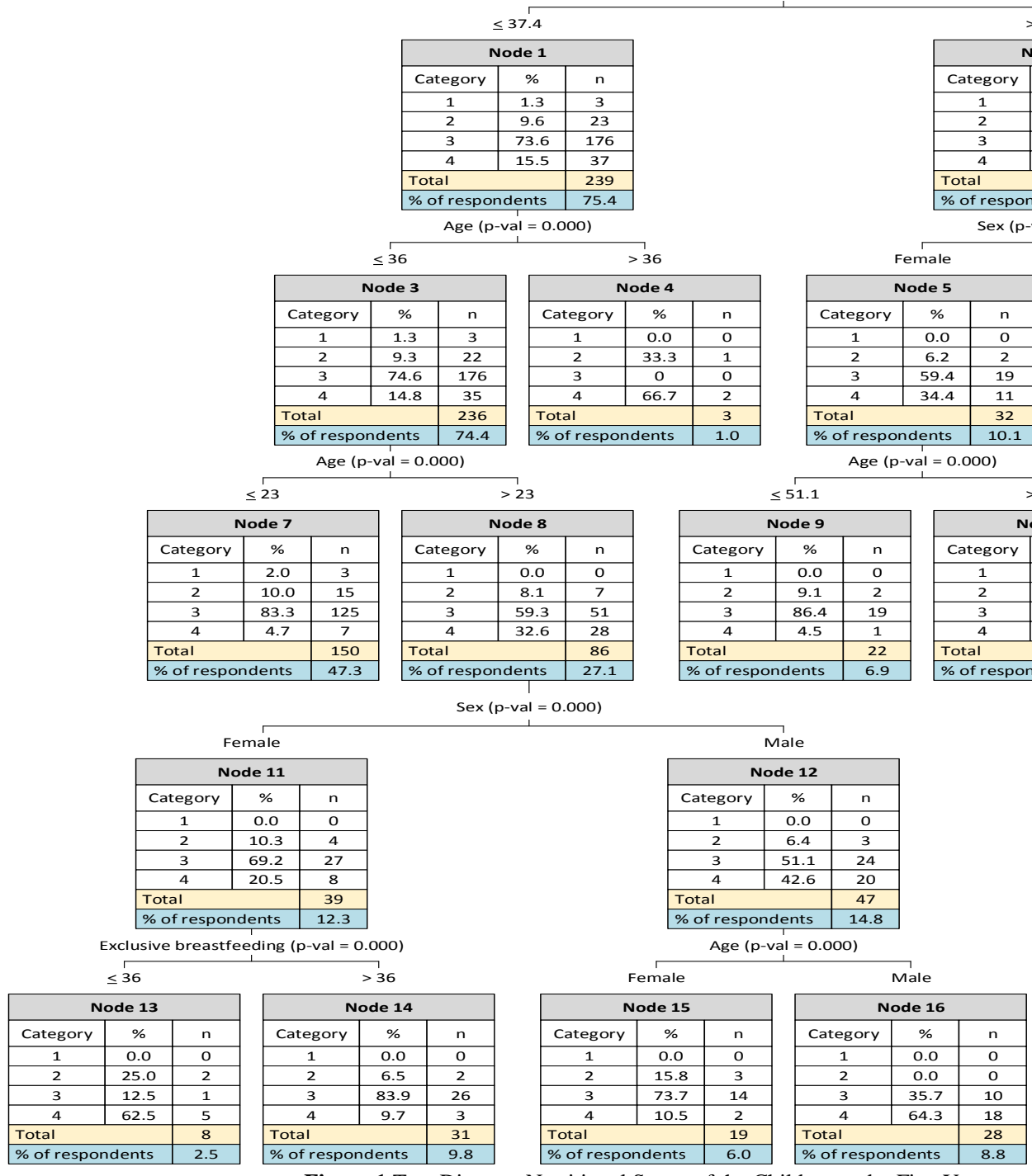

Figure 1.Tree Diagram Nutritional Status of the Children under Five Years 
The results were highly accurate, where $83 \%$ of the children were classified correctly. Complete results of the comparison of observed values with estimated values are presented in Table 5.

Furthermore, based on the distribution of children in each node in the tree diagram (Figure 1), the following facts could be inferred that of all children suffering from severely underweight cases, all were under 36 months of age; and of 25 underweight children, 22 were under 36 months. In conclusion, cases of severely underweight and underweight were common among children under three years of age or younger. Otherwise it can be seen that among female children whose ages were less than 36 months, the case of overweight was found in children who were not exclusively breastfed. Besides that, overweight cases were more commonly found in male children and all children over 51.1 months old had experienced over nutrition.

\section{DISCUSSION}

The results of the QUEST method analysis demonstrated that age becomes one factor that significantly influenced the nutritional status of children under five years of age, where the prevalence of severely underweight and underweight appeared to be higher in group of children under three years of age. This problem emerged because children under three years are more susceptible to suffering from various diseases such as diarrhea and ISPA. Inadequate knowledge and improper practices most probably become significant barriers to improve children's nutrition. Mothers seemed to have not realized the importance of nutrition during pregnancy and the first two years of a child's life.

Another variable that had a significant influence was the exclusive breastfeeding. The result of this current study was in line with Giri's and Susilawati's findings[11, 17] but different from other studies [18]. This study indicated a tendency that the overweight problem was encountered by children who did not receive exclusive breastfeeding. This can be expected to occur because they tended to consume formula milk in a high frequency. The impact of such excessive consumption of infant formula provides a topic for further studies.

An exclusive breastfeeding program had been launched worldwide, including in Indonesia. Newborn infants should have a sufficient intake of breast milk until the age of 6 months. Subsequently, the infants can only be given complementary food in addition to breast milk after they are 6 months old in order to meet body nutritional needs $[8,10,11]$. This program had been established to become one of the children's malnutrition anticipatory solutions.

With regard to a global public health recommendation, exclusively breastfeeding infants for the first six months of their lives would allow them to achieve optimal growth, development, and health. Thereafter, to meet their evolving nutritional needs, infants should receive safe and nutritionally adequate complementary foods while breastfeeding continues for up to two years of age or beyond [19,20,21].

Furthermore, this study indicated that severely underweight and underweight cases tended to be more common in female children. This was in contrast to some previous studies, which found that the incidence of malnutrition is more common in male children[22, 23]. This can also be the subject of further study.

Based on these results, it is recommended that the government, through the health ministry, community, and health workers, implements special programs that can improve the nutritional status of children, especially for children under three years of age. The government may need to improve their public campaign on the exclusively breastfeeding for the children so that mothers could be more motivated to breastfeed their children, and the children may have the good nutritional status. 


\section{CONCLUSIONS}

The distribution of nutritional status for the observed children under five years in the research are severely underweight $(0.94 \%)$, underweight $(7.89 \%)$, normal $(62.15 \%)$, and overweight (29.02\%). In modelling the nutritional status of children under five based on weight-for-age score, three variables (age, sex, and exclusive breastfeeding) are considered to have affected the nutritional status of under-five children. Children under three years of age were proven to be more vulnerable to have underweight and severely underweight status. The overweight cases are mostly found in non-exclusively breastfed female children under three years of age. The underweight and severely underweight were mostly found in the female, but the overweight cases were mostly found in male children.

\section{Significance Statement}

This study discovers that the QUEST method can be beneficial for developing techniques in analyzing causal relation in public health research. In this research, the data are grouped based on the significant variables that affect the nutritional status of the children. The analysis can be conducted comprehensively and systematically. This process is carried out in each new group recursively, and significant variables may be dissimilar for different groups. In many previous studies, analysis of independent variables was performed for the whole data without considering the variation of data. This study will help the researcher to uncover the critical areas of predictive use of tree diagram analysis for health research that many researchers have not yet explored.

Acknowledgement: The authors are grateful to Andalas University for supporting this research.

\section{Conflict of Interest: None}

Source of Funding: None

\section{REFERENCES}

1. Aritonang, E.; Sari Siregar, E. I. S.; Nasution, E. The Relationship of Food Consumption and Nutritional Status on Employee of Health Polytechnic Directorate Health Ministry Medan. International Journal on Advanced Science, Engineering and Information Technology 2016, 6 (1), 104-106.

2. Hoddinott, J.; Maluccio, J. A.; Behrman, J. R.; Flores, R.; Martorell, R. Effect of a Nutritional Intervention During Early Childhood on Economic Productivity in Guatemalan Adults. Lancet 2008, 371 (9610), 411-416.

3. Strauss, J.; Thomas, D. Health, Nutrition, and Economic Development. J. Econ. Lit. 1998, 36 (2), 766-817.

4. Monteiro, C. A.; Benicio, M. H. D.; Konno, S. C.; Silva, A. C. F.; Lima, A. L. L.; Conde, W. L. Causes for the Decline in Child Under nutrition in Brazil. Rev. Saude Pública 2009, 43 (1), 35-43.

5. The Ministry of Health of Republic of Indonesia Handbook of Nutritional Status Monitoring Results 2015. http://www.gisi.kemkes.go.id, 2016.

6. The Ministry of Health of Republic of Indonesia Handbook of Nutritional Status Monitoring Results 2016. http://www.gisi.kemkes.go.id, 2017.

7. UNICEF (United Nations Children's Fund), Strategies of Improving Nutrition of Children and Women in Developing Countries; United Nations Children's Emergency Fund: New York, 1990.

8. Brhane, G.; Regassa, N. Nutritional Status of Children Under Five Years of Age in Shire Indaselassie, North Ethiophia: Examining the Prevalence and Risk Factors. Kontact. http://www.elsevier.com/locate/kontakt; Vol. 16, pp e161-e170, 2014.

9. Mazarina, D. Analysis of Influential Factors on Nutritional Status of Under Fives in Rural Areas. J. Technol. and Vocat. 2010, 33 (2), Sept, 183-192.

10. Semba, R. D.; de Pee, S.; Sun, K.; Sari, M.; Akhter, N.; Bloem, M. W. Effect of Parental Formal Education on Risk of Child Stunting in Indonesia and Bangladesh: A CrossSectional Study. Lancet 2008, 371 (9609), 322-328.2008.

11. Giri, M. K. W.; Muliarta, I. W.; Wahyuni, D. S. The Relationship Between Exclusive 
Breastfeeding with Nutritional Status of Children Aged 6-24 Months in Kampung Kajanan, Buleleng. J. SainsTeknol. 2013, 1 (1), 184-192.

12. Latiff, L. A.; Soo Lee, M. H.; Mazidi, Mohsen, Majid Ghayour Mobarhan, GolsaTabatabaei, Gordon Ferns4 Determinants of Nutritional Status in Children Living in Mashhad, Iran. Tahereh Shafieian. Int. J. Pediatr., 1 (2), 9-18. http://ijp.mums.ac.ir.Dec 2013.

13. Ramezankani A. et all, Decision Tree-Based Modelling For Identification of Potential Interactions Between Type 2 Diabetes Risk Factors: A Decade Follow-Up in A Middle East Prospective Cohort Study .BMJ Open 2016, 6 (12), 1-13.

14. Abdurrahman, M.R; Ispriyanti,D; Prahutama, A. Pembentukan Pohon Klasifikasi Biner dengan Algoritma QUEST (Quick, Unbiased, And Efficient Statistical Tree) Pada Data Pasien Liver. Jurnal Gaussian, 2014, 3(4), 731-739.

15. Loh, W.-Y.; Shih, Y.-S. Split Selection Methods for Classification Trees. Stat. Sin. 1997, 7, 815-840.

16. Loh, W. Y., Classification and Regression Tree Methods (In Encyclopedia of Statistics in Quality and Reliability, Ruggeri, Kenett and Faltin(eds.), 315-323, Wiley, 2008). Department of the Statistics University of Wisconsin Madison.

17. Susilowati; Kusharisupeni; Fikawati, S.; Achmad, K. Breastfeeding Duration and Children's Nutritional Status at Age 12-24
Months. Pediatria Indonesia 2010, 50 (1), 56-61.

18. Arpadi, S.; Fawzy, A.; Aldrovandi, G. M.; Kankasa, C.; Sinkala, M.; Mwiya, M.; Thea, D. M.; Kuhn, L. Growth Faltering Due to Breastfeeding Cessation in Uninfected Children Born to HIV-Infected Mothers in Zambia. Am. J. Clin. Nutr. 2009, 90 (2), 344-353.

19. WHO Indicators for Assessing Infant and Young Child Feeding Practices part 3. Ctry. Profiles; WHO: Malta 2010.

20. WHO; World Health Organization: Geneva Library Cataloguing in Publication Data, 2009 Infant, and Young Child Feeding.

21. United Nations Children's Fund (UNICEF), Infant and Young Child Feeding; United Nations Children's Fund (UNICEF), June 2012.

22. Aries, M. Hardinsyah, and H. Tuhiman. Determinant Underweight and Stunting Children Aged 0-36 Months Based on the Data of Conditional Family Program (CFP) 2007. J. Nutr. and Food March 2012, 7 (1), 19-26.

23. Sartika, R. A. D. An Analysis of the Usage of Health Service Related to Nutritional Status of Under-Five Years Old Children. Natl. Public Health J. 2010, 5 (2), 76-83.

How to cite this article: Rahmia I, Yozzaa H, Rahmy HA. Predicting children's nutritional status using QUEST method. International Journal of Science \& Healthcare Research. 2021; 6(3): 141-148. DOI: https://doi.org/ 10.52403/ijshr.20210723 